\title{
Rationale and design of MinerAlocorticoid Receptor antagonist Tolerability Study-Heart Failure (ARTS-HF): a randomized study of finerenone vs. eplerenone in patients who have worsening chronic heart failure with diabetes and/or chronic kidney disease
}

\author{
Bertram Pitt ${ }^{1 *}$, Stefan D. Anker ${ }^{2}$, Michael Böhm³ ${ }^{3}$, Mihai Gheorghiade ${ }^{4}$, Lars \\ Køber ${ }^{5}$, Henry Krum ${ }^{6}$, Aldo P. Maggioni ${ }^{7}$, Piotr Ponikowski ${ }^{8}$, Adriaan A. Voors ${ }^{9}$, \\ Faiez Zannad ${ }^{10}$, Christina Nowack ${ }^{11}$, So-Young Kim ${ }^{11}$, Alexander Pieper ${ }^{12}$, Nina \\ Kimmeskamp-Kirschbaum ${ }^{13}$, and Gerasimos Filippatos ${ }^{14}$
}

${ }^{1}$ University of Michigan Medical School, 1500 E Medical Center Drive, 3910 Tauman Ctr, Ann Arbor, MI, 48109 0366, USA; ${ }^{2}$ Department of Innovative Clinical Trials, University Medical Centre Göttingen, Göttingen, Germany; ${ }^{3}$ Universitätskliniken des Saarlandes, Klinik für Innere Medizin III, Homburg, Germany; ${ }^{4}$ Feinberg School of Medicine, Northwestern University, Chicago, IL, USA; ${ }^{5}$ Heart Centre, Rigshospitalet, University of Copenhagen, Denmark; ${ }^{6}$ Centre of Cardiovascular Research and Education in Therapeutics, Monash University, Melbourne, Australia; ${ }^{7}$ Research Centre of the Italian Association of Hospital Cardiologists, Florence, Italy; ${ }^{8}$ Medical University, Clinical Military Hospital, Wrocław, Poland; ${ }^{9}$ University Medical Centre Groningen, Groningen, Netherlands; ${ }^{10} \mathrm{CHU}$ Department of Cardiology, Université de Lorraine, Nancy, France; ${ }^{11}$ Global Clinical Development, Bayer HealthCare AG, Leverkusen, Germany; ${ }^{12}$ M.A.R.C.O. GmbH \& Co. KG, Düsseldorf, Germany; ${ }^{13}$ Global Research \& Development Statistics, Bayer HealthCare AG, Leverkusen, Germany; and ${ }^{14}$ Department of Cardiology, Attikon University Hospital, Athens, Greece

Received 16 September 2014; revised 18 November 2014; accepted 21 November 2014

Aims

To investigate the safety and potential efficacy of the novel non-steroidal mineralocorticoid receptor antagonist finerenone in patients with worsening chronic heart failure and reduced left ventricular ejection fraction (HFrEF) and at high risk of hyperkalaemia and worsening renal dysfunction.

Methods

and results

The MinerAlocorticoid Receptor antagonist Tolerability Study-Heart Failure (ARTS-HF; NCT01807221) is a multicentre, randomized, double-blind, active-comparator-controlled, six-parallel-group, phase $2 \mathrm{~b}$ dose-finding study. In total, 1060 patients with HFrEF and concomitant type 2 diabetes mellitus and/or chronic kidney disease (CKD) will be randomized within 7 days of emergency presentation to hospital for worsening chronic HF to receive finerenone (one of five doses in the range $2.5-20.0 \mathrm{mg}$ once daily) or eplerenone ( $25 \mathrm{mg}$ every second day to $50 \mathrm{mg}$ once daily for 90 days). The primary objective is to investigate the safety and potential efficacy (measured as the percentage of individuals with a decrease in plasma $\mathrm{N}$-terminal pro-B-type natriuretic peptide [NT-proBNP] of more than $30 \%$ relative to baseline at day $90 \pm 2$ ) of different oral doses of finerenone compared with eplerenone. Other objectives are to assess the effects of finerenone on a composite clinical endpoint (death from any cause, cardiovascular hospitalizations, or emergency presentations for worsening chronic HF), and on changes in health-related quality of life from baseline.

Conclusions ARTS-HF is the first phase $2 b$ clinical trial to investigate the effects of finerenone on plasma NT-proBNP in a high-risk population of patients who have worsening chronic HF with type 2 diabetes mellitus and/or CKD presenting at the emergency department.

Keywords

Antagonist • Chronic kidney disease • Heart failure • Mineralocorticoid receptor • Type 2

diabetes mellitus

*Corresponding author: Tel: +1 734 9365260, Fax: +1 734 9365256, E-mail: bpitt@med.umich.edu 


\section{Introduction}

The steroidal mineralocorticoid-receptor antagonists (MRAs) spironolactone and eplerenone reduce mortality and hospitalizations for heart failure (HF) in patients with $\mathrm{HF}$ and a reduced ejection fraction $(\mathrm{HFrEF})^{1,2}$ and are a class $1 \mathrm{~A}$ recommendation for the treatment of this patient population in international guidelines. $^{3-5}$ However, steroidal MRAs significantly increase the risk of hyperkalaemia and worsening renal function. ${ }^{6,7}$ Thus, they are still underused and often discontinued once administered. ${ }^{8}$ This is particularly the case in patients already at high risk of hyperkalaemia, including those with type 2 diabetes mellitus (T2DM) and chronic kidney disease (CKD), who, at best, can usually tolerate treatment with only a low dose of an MRA in combination with an angiotensin-converting enzyme (ACE) inhibitor and/or an angiotensin receptor blocker (ARB).

Patients with worsening chronic HFrEF who require hospitalization or intensified ambulatory treatment have a very increased risk of post-discharge mortality and hospital readmission, with rates as high as $15 \%$ and $30 \%$, respectively, within $60-90$ days. $^{9-12}$ The high morbidity and mortality in patients with worsening chronic HF represent an unmet need in the treatment of these patients. As aldosterone levels are elevated in HF, the mineralocorticoid receptor (MR) may be an important therapeutic target in patients with worsening HFrEF. ${ }^{4}$ However, because the prevalence of CKD and/or T2DM is high in patients hospitalized for worsening chronic $\mathrm{HFrEF}{ }^{13,14}$ the risk of hyperkalaemia and worsening renal function may also be high if they were to be treated with currently available MRAs, especially early during their hospital stay when renal function may be fluctuating. There is therefore a need for a new MRA that, like the currently available steroidal MRAs, ${ }^{7,15}$ is able to improve cardiovascular outcomes, but is less likely to induce hyperkalaemia in patients with worsening chronic HFrEF and concomitant T2DM and/or CKD.

Finerenone (BAY 94-8862) is a next-generation, oral, selective, non-steroidal MRA. In recent preclinical rat studies, chronic finerenone treatment prevented the development of functional and structural heart and kidney damage more efficiently than the steroidal MRA eplerenone, when comparing equinatriuretic doses. ${ }^{14} \mathrm{C}$-finerenone distributes equally to the heart and kidney, ${ }^{16}$ in contrast to eplerenone, which demonstrates at least a threefold greater accumulation in the kidney than in the heart of conscious rats. ${ }^{17}$ Finerenone combines spironolactone's potency with eplerenone's selectivity and, based on its non-steroidal chemical structure, ${ }^{18}$ it may have an improved cardiac vs. renal activity ratio (relative renal sparing) because of a combination of physicochemical properties that influence plasma transport and tissue penetration and differential affinity of the MR-drug complex for tissue-specific cofactors. Therefore, finerenone may offer end-organ protection with a reduced risk of electrolyte disturbances (and therefore hyperkalaemia) compared with steroidal MRAs. ${ }^{16}$

Finerenone has been previously studied in 392 patients with stable HFrEF and mild to moderate CKD (estimated glomerular filtration rate [eGFR] 60 to $<90 \mathrm{~mL} / \mathrm{min} .1 .73 \mathrm{~m}^{2}$ and $30-60 \mathrm{~mL} / \mathrm{min} .1 .73 \mathrm{~m}^{2}$, respectively). In the phase $2 \mathrm{a}$
MinerAlocorticoid Receptor Antagonist Tolerability Study (ARTS; NCT01345656), finerenone $5.0-10.0 \mathrm{mg} /$ day reduced plasma natriuretic peptides levels and albuminuria to at least the same magnitude as spironolactone $25-50 \mathrm{mg} /$ day, but was associated with a significantly smaller mean increase in serum potassium concentration $\left(\left[\mathrm{K}^{+}\right]\right)$and smaller decreases in eGFR. ${ }^{19}$

In patients with worsening chronic HF, baseline serum levels and the magnitude of change in the concentration of natriuretic peptides are known to provide incremental prognostic value, ${ }^{20-22}$ and thus represent predictors of adverse outcomes. ${ }^{20-24}$ Against this background, ARTS-Heart Failure (ARTS-HF) is a dose-finding study designed to investigate the effects of 90 days of finerenone (dose range, $2.5-20 \mathrm{mg} /$ day) or eplerenone (dose range, $25 \mathrm{mg}$ every other day to $50 \mathrm{mg} /$ day) on plasma $\mathrm{N}$-terminal pro-B-type natriuretic peptide (NT-proBNP) concentrations in high-risk patients with worsening chronic HFrEF and concomitant T2DM and/or CKD.

\section{Methods}

\section{Study design}

ARTS-HF (ClinicalTrials.gov identifier: NCT01807221) is a multicentre, randomized, double-blind, active-comparator-controlled, six-parallel-group, phase $2 b$ dose-finding study. Patients with worsening chronic HFrEF who also have T2DM with CKD, T2DM without CKD, or moderate CKD alone will receive finerenone at a dose of 2.5-20.0 mg once daily or eplerenone at a dose of $25 \mathrm{mg}$ every second day, $25 \mathrm{mg}$ once daily, or $50 \mathrm{mg}$ once daily.

It is intended that 1510 patients will be screened and 1060 will receive treatment with study drug.

\section{Objectives}

The primary objective of the study is to investigate the safety and potential efficacy (measured as the percentage of individuals with a decrease in plasma NT-proBNP of more than $30 \%$ relative to baseline at visit 9 [day $90 \pm 2$ ]) of different oral doses of finerenone given once daily.

Further exploratory objectives are to assess:

- effects on a composite endpoint of death from any cause, cardiovascular hospitalizations, or emergency presentations for worsening HFrEF until visit 9

- effects on plasma B-type natriuretic peptide (BNP) and NT-proBNP at visit 5 (day $30 \pm 2$ ), visit 7 (day $60 \pm 2$ ), and visit 9 (with decreases or increases in laboratory results monitored continually throughout the trial)

- effects on other efficacy biomarkers (galectin 3 and $\mathrm{N}$-terminal procollagen III propeptide) at baseline, visits 5, 7 and 9, and follow-up

- effects on safety (troponin T and cystatin C) biomarkers at baseline, visits 5, 7 and 9, and follow-up, on vital signs at baseline, visits 3, 4, 5,7 and 9 , and follow-up, on laboratory safety results at every visit, including on serum $\mathrm{K}^{+}$, creatinine levels and eGFR, and on adverse events at every visit, including on the predefined adverse events of special safety interest i.e. (an increase in blood $\left[\mathrm{K}^{+}\right] \geq 5.6 \mathrm{mmol} / \mathrm{L}$ leading to discontinuation or emergency presentation of worsening chronic HF after the start of study drug treatment) 
- change in health-related quality of life (HRQoL) from baseline to visit 5 and visit 9 using the Kansas City Cardiomyopathy Questionnaire and EuroQoL Group five-dimension, three-level questionnaire.

Blinded adjudication of all hospitalizations and deaths will be performed by a central committee.

\section{Patients}

Adults with worsening chronic HFrEF requiring emergency presentation to hospital and treatment with intravenous diuretics, who meet all of the inclusion criteria and none of the exclusion criteria (Table 1), are eligible for the treatment phase of the study. Briefly, patients must have T2DM and/or CKD, have been treated with evidence-based therapy for HF for at least 3 months before emergency presentation to hospital, and have a medical history of a left ventricular EF of $40 \%$ or less within the last 12 months. Patients with acute de novo HF or acute inflammatory heart disease, acute coronary syndromes in the last 30 days before the screening visit, cardiogenic shock or valvular heart disease requiring surgical intervention, those with a left ventricular assist device or awaiting heart transplantation, and patients who have experienced a stroke or transient ischaemic attack within 3 months before screening will not be eligible for participation.

It should be noted that, although atrial fibrillation (AF) is not an exclusion criterion, the number of patients with AF documented from initial emergency presentation to hospital up to randomization will be controlled within the study. The proportion of patients with AF enrolled in the study will be limited to no more than $45 \%$ of the planned total number of randomized patients at the end of the study.

\section{Study medication}

Initially, patients were randomized 1:1:1 in the 7-day period following emergency presentation to hospital to receive finerenone oral, immediate-release tablets once daily at a dose of $2.5 \mathrm{mg}$ or $5.0 \mathrm{mg}$, or oral eplerenone every second day at a dose of $25 \mathrm{mg}$. Once approximately 300 patients were randomized, the safety and tolerability (in particular, changes in serum $\left[\mathrm{K}^{+}\right]$compared with baseline, the number of patients with hyperkalaemia $\left[\left[\mathrm{K}^{+}\right] \geq 5.6 \mathrm{mmol} / \mathrm{L}\right]$, the number of patients with a decrease in eGFR of $\geq 30 \%$, and the incidence of adverse events related to worsening renal function) of the initial doses were assessed by an independent Data and Safety Monitoring Board (DSMB) in January 2014. Based on this safety and tolerability assessment, the DSMB decided that the following pre-planned treatment arms could be introduced into the study: finerenone $7.5 \mathrm{mg}$, uptitrated to $15.0 \mathrm{mg}$ at visit 5 (day $30 \pm 2$ ); finerenone $10.0 \mathrm{mg}$, uptitrated to $20.0 \mathrm{mg}$ at visit 5 ; finerenone $15.0 \mathrm{mg}$, uptitrated to $20.0 \mathrm{mg}$ at visit 5 (Figure 1). Randomization was accordingly adapted to obtain approximately equal sample sizes across all finerenone treatment groups and a randomization ratio of 1:1.5 between each finerenone treatment group and the eplerenone treatment group by the end of the study. The randomization was stratified by region, comorbidities (CKD, T2DM, or both) and MRA use at emergency presentation to hospital [MRA naïve (no use of an MRA in the 5 days before emergency presentation) or previous MRA use (use of an MRA in the 5 days prior to emergency presentation)].

Patients will begin treatment with finerenone or eplerenone in addition to their standard therapy for HF and will receive the doses described above throughout the acute/vulnerable phase (days 1-30). Provided that serum/plasma $\left[\mathrm{K}^{+}\right]$is $5.0 \mathrm{mmol} / \mathrm{L}$ or less in the locally analysed sample at visit 5 (day $30 \pm 2$ ), study drug will be uptitrated according to the schedule in Figure 1.

During the chronic phase (days 31-90), there will be another up-titration (eplerenone group) or sham up-titration (finerenone group) depending on the $\left[\mathrm{K}^{+}\right]$in the locally analysed sample at visit 7 (day $60 \pm 2$ ), according to the schedule in Figure 1.

\section{Serum/plasma potassium monitoring}

Patients will maintain their normal diet throughout the study and will not be given any specific advice on dietary sodium or potassium restrictions. If a patient undergoes a change in clinical status that is known to influence serum/plasma electrolyte levels or fluid balance (e.g. vomiting and/or diarrhoea for $>1$ day), it is recommended that serum/plasma $\left[\mathrm{K}^{+}\right]$is reassessed as soon as possible after the acute event. Any reassessment of serum/plasma $\left[\mathrm{K}^{+}\right]$must be analysed locally and centrally. At each scheduled visit, blood samples will be collected for measurement of parameters including serum/plasma $\left[\mathrm{K}^{+}\right]$. Investigators should stop the study drug permanently in the event of a confirmed $\left[\mathrm{K}^{+}\right]$of $5.6 \mathrm{mmol} / \mathrm{L}$ or more. Such a discontinuation must be reported within $24 \mathrm{~h}$ as a serious adverse event. A summary of blood potassium monitoring is given in Figure 2.

\section{Investigations}

Patients will be assessed at the screening visit, at baseline/day 1 (start of drug administrations), and according to the schedule shown in Table 2. A follow-up visit will be scheduled $30 \pm 5$ days after the last intake of study medication. Patients who discontinue the study prematurely will also be assessed as soon as possible after discontinuation.

Details of the assessments made at each visit are shown in Table 2 and summarized in the Supporting Information, Figure S1. Safety (troponin T and cystatin C) and efficacy (plasma BNP, NT-proBNP, galectin 3 , and $\mathrm{N}$-terminal procollagen III propeptide, biomarkers will be measured at baseline, at visits 5,7 and 9 and at follow-up. Serum $[\mathrm{K}+]$, serum creatinine concentration, and eGFR will be measured at each visit. Furthermore, any changes (i.e. decreases or increases) in laboratory results will be monitored continually throughout the trial.

\section{Adverse events monitoring}

Monitoring in ARTS-HF is coordinated by an independent DSMB, comprising cardiologists, endocrinologists and nephrologists, as well as a biostatistician (DSMB members are listed in the Suppporting Information, Appendix S1). Meetings of the DSMB will take place approximately every other month. In addition, an overview of serious adverse events in the two studies will be sent to the chair of the DSMB on a weekly basis.

\section{Statistical considerations}

\section{Statistical methodology}

There will be four analysis sets: the safety set (all patients who have taken at least one dose of study drug and for whom data following treatment are available); the full analysis set [all individuals from the safety set with baseline and at least one post-baseline plasma NT-proBNP value or who died or experienced permanent ( $\geq 5$ consecutive days) withdrawal of study drug after cardiovascular hospitalization or after emergency presentation for worsening chronic HF]; the per protocol set (all patients from the full analysis set with valid plasma 
Table 1 Inclusion and exclusion criteria

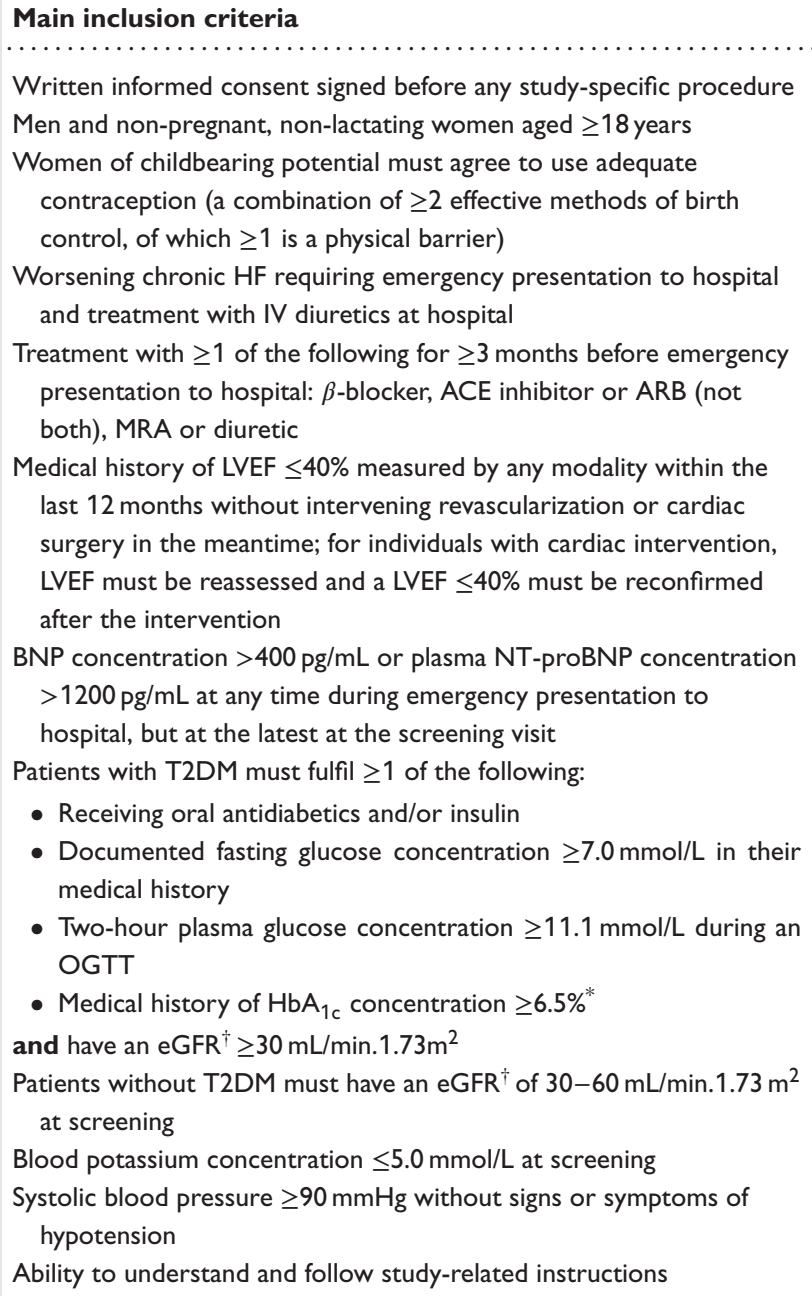

- Documented fasting glucose concentration $\geq 7.0 \mathrm{mmol} / \mathrm{L}$ in their medical history

- Two-hour plasma glucose concentration $\geq 11.1 \mathrm{mmol} / \mathrm{L}$ during an OGTT

- Medical history of $\mathrm{HbA}_{1 \mathrm{c}}$ concentration $\geq 6.5 \%$ *

and have an $\mathrm{eGFR}^{\dagger} \geq 30 \mathrm{~mL} / \mathrm{min} .1 .73 \mathrm{~m}^{2}$

Patients without T2DM must have an eGFR ${ }^{\dagger}$ of $30-60 \mathrm{~mL} / \mathrm{min} .1 .73 \mathrm{~m}^{2}$ at screening

Blood potassium concentration $\leq 5.0 \mathrm{mmol} / \mathrm{L}$ at screening

Systolic blood pressure $\geq 90 \mathrm{mmHg}$ without signs or symptoms of hypotension

Ability to understand and follow study-related instructions

ACE, angiotensin converting enzyme; ACS, acute coronary syndromes; ARB, angiotensin receptor blocker; ASA, acetylsalicylic acid; BNP, B-type natriuretic peptide; CKD, chronic kidney disease; CYP, cytochrome P450; eGFR, estimated glomerular filtration rate; $\mathrm{HbA}_{1 \mathrm{c}}$, glycated haemoglobin; $\mathrm{HF}$, heart failure; IV, intravenous; LVEF, left ventricular ejection fraction; MRA, mineralocorticoid receptor antagonist; NSAID, non-steroidal anti-inflammatory drug; NT-proBNP, N-terminal proBNP; OGTT, oral glucose tolerance test; T2DM, type 2 diabetes mellitus; TIA, transient ischaemic attack.

"As defined in the National Glycohemoglobin Standardization Program or the Diabetes Control and Complications Trial.

As measured using the Modification of Diet in Renal Disease equation.

As defined by the European Society of Cardiology ${ }^{40}$ and American College of Cardiology/American Heart Association ${ }^{41}$ guidelines.

NT-proBNP data at visit 7 or later and no major protocol deviations); and the pharmacokinetic analysis set (all patients with at least one valid finerenone plasma concentration measurement and without protocol deviations that would interfere with evaluation of pharmacokinetic data). In the full analysis set, patients who die or who experience permanent withdrawal of study drug after cardiovascular hospitalization or after emergency presentation for worsening chronic HF will be considered as non-responders to avoid a bias towards treatment responders in the assessment of the primary efficacy variable.

The primary efficacy variable, the percentage of patients with a decrease in plasma NT-proBNP of more than $30 \%$ relative to baseline at visit 9 , will be assessed in the full analysis set (primary analysis) and the per protocol set (supportive analysis).

Separate $\chi^{2}$ tests with continuity correction will be applied to compare each finerenone group with the eplerenone group. The

\section{Main exclusion criteria}

Acute de novo HF or acute inflammatory heart disease

$\mathrm{ACS}^{\ddagger}$ in the last 30 days before the screening visit

Cardiogenic shock

Valvular heart disease requiring surgical intervention during the course of the study

Patients with a left ventricular assistance device or awaiting heart transplantation

Stroke or $\mathrm{TIA} \leq 3$ months before the screening visit

Known hypersensitivity to the study drug (active substance or excipients) or eplerenone

Addison's disease

Acute infectious disease requiring IV antibiotics within the last $24 \mathrm{~h}$ before randomization

Dialysis for acute renal failure within the previous 3 months before emergency presentation to hospital

Hepatic insufficiency (Child-Pugh B or C)

Requirement for any IV vasodilator, any IV natriuretic peptide within the $24 \mathrm{~h}$ before randomization, or any IV positive inotrope within the 14 days before dosing with study drug

Treatment with either spironolactone or eplerenone that cannot be discontinued $48 \mathrm{~h}$ or $24 \mathrm{~h}$, respectively, before randomization and for the duration of the treatment period

Treatment with any renin inhibitor or potassium-sparing diuretic that cannot be discontinued $24 \mathrm{~h}$ before randomization and for the duration of the treatment period

Treatment with high-dose ASA ( $>500 \mathrm{mg} /$ day) or another NSAID

Treatment with potent CYP3A4 inhibitors or inducers or strong CYP2C8 inhibitors (all must be stopped $\geq 7$ days before randomization)
Cochran-Mantel-Haenszel procedure will also be used to assess finerenone vs. eplerenone stratified by region, comorbidities, and MRA use at emergency presentation to hospital. Both tests will be performed with a one-sided significance level of $5 \%$. In cases where the expected number of patients in at least one cell of a $2 \times 2$ contingency table is less than 5, Fisher's exact test will be used. In the primary analysis, a last observation carried forward (LOCF) method will be applied, whereby the highest plasma NT-proBNP value from the premature discontinuation measurement and the follow-up measurement will be used to impute missing plasma NT-proBNP values at visit 9 for individuals who prematurely terminated the study. Sensitivity analyses will be conducted.

These analyses will be repeated for the percentage of patients with a decrease in plasma NT-proBNP of $50 \%$ or more relative to baseline at visit 9 (without the LOCF imputation) and similar analyses will 


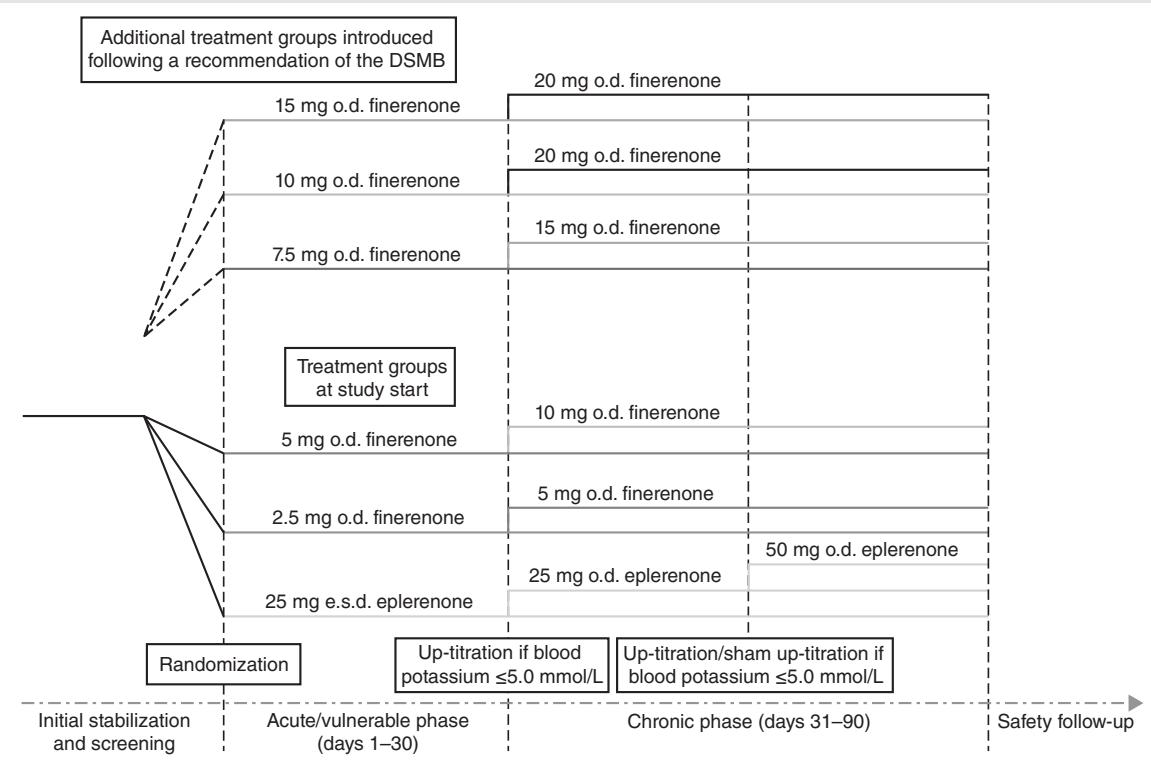

Figure 1 Study flow chart. The study enrols patients with chronic heart failure with reduced ejection fraction who also have type 2 diabetes mellitus (T2DM) with chronic kidney disease (CKD), T2DM without CKD, or moderate CKD alone. DSMB, Data and Safety Monitoring Board; e.s.d., every second day; o.d., once daily.

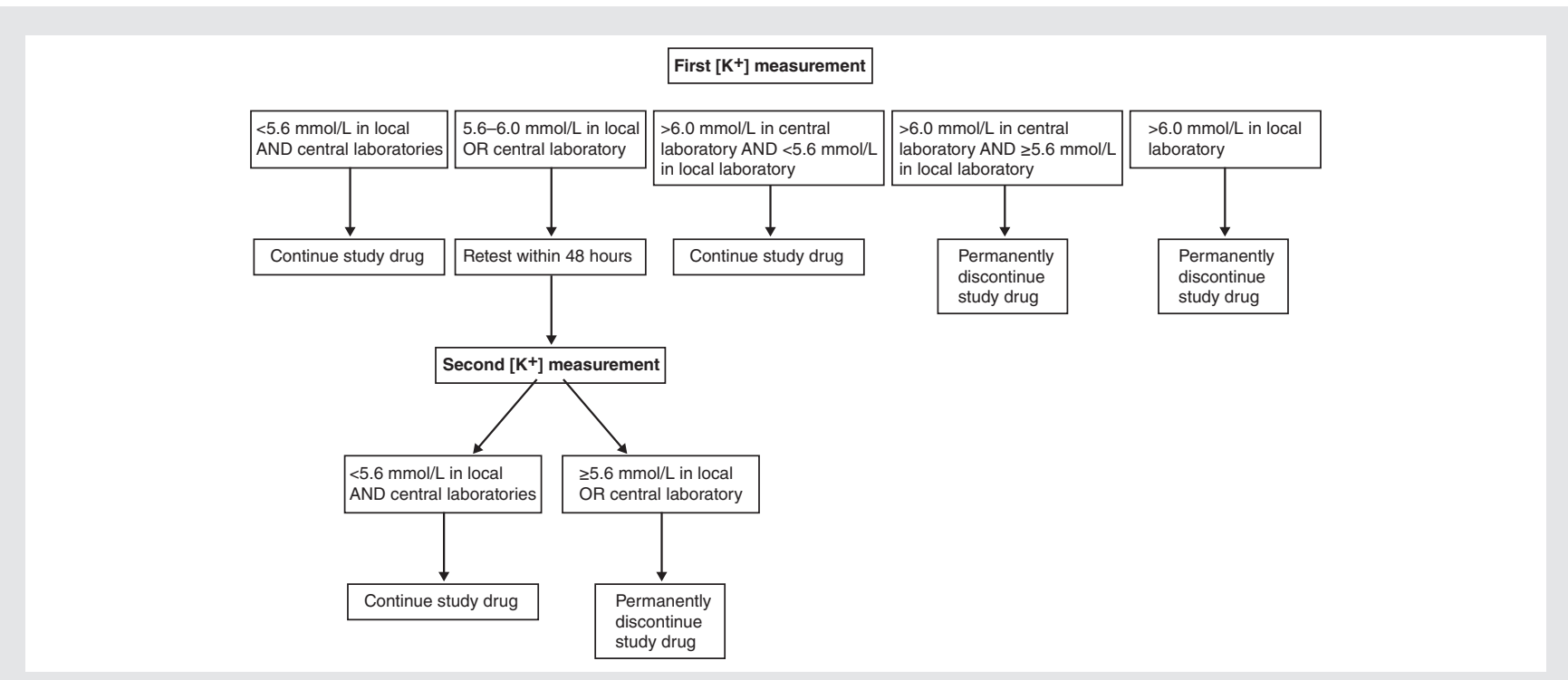

Figure 2 Monitoring of blood potassium concentration $\left[\mathrm{K}^{+}\right]$during the treatment period.

also be conducted for the decreases in plasma NT-proBNP relative to baseline at visits 5 and 7. Absolute changes in plasma NT-proBNP from baseline to visits 5,7 and 9 will be assessed using separate analysis of covariance (ANCOVA) models with the factors treatment group, region, comorbidities, MRA use at emergency presentation to hospital, $\mathrm{AF}$ and the baseline value as covariates. In cases where the data are not approximately normally distributed, non-parametric methods or transformation of the data will be applied.

Further exploratory efficacy variables will be analysed in the full analysis and per protocol sets. Analyses of all safety variables will be performed in the safety set. Changes in biomarkers from baseline to visits 5,7 , and 9 and in HRQoL scores to visits 5 and 9 will be investigated using separate ANCOVA models.

Time to cardiovascular hospitalization, emergency presentation for worsening chronic HF, all-cause death, cardiovascular death and the time to the first event of composites of these events will be estimated based on the life-table and Kaplan-Meier methods. Differences between each finerenone group and the eplerenone group will be tested with the log-rank test.

The incidence of patients with a serum/plasma $\left[\mathrm{K}^{+}\right]$of $5.6 \mathrm{mmol} / \mathrm{L}$ or greater or more than $6.0 \mathrm{mmol} / \mathrm{L}$, or in different eGFR categories or categories of creatinine increase, will be investigated with 
Table 2 Schedule of assessment

\begin{tabular}{|c|c|c|c|c|c|c|c|c|c|c|c|c|}
\hline & \multicolumn{10}{|l|}{ Visit } & \multirow{2}{*}{$\begin{array}{l}\text { PD } \\
\text { visit }\end{array}$} & \multirow{2}{*}{$\begin{array}{l}\text { Follow- } \\
\text { up }\end{array}$} \\
\hline & Screening & 1 (BL) & 2 (Dis) $^{*}$ & 3 & $4^{\dagger}$ & 5 & $6^{*}$ & 7 & $8^{\S}$ & 9 & & \\
\hline Day & $\leq-7$ & 1 & $2-6$ & $7 \pm 2$ & $14 \pm 2$ & $30 \pm 2$ & $37 \pm 2$ & $60 \pm 2$ & $67 \pm 2$ & $90 \pm 2$ & & \\
\hline Informed consent & $\mathrm{X}$ & & & & & & & & & & & \\
\hline Demographic data & $x$ & & & & & & & & & & & \\
\hline Smoking history and alcohol & $x$ & & & & & & & & & & & \\
\hline Medical and surgical history & $x$ & & & & & & & & & & & \\
\hline Prior medications & $x$ & & & & & & & & & & & \\
\hline Local laboratory blood sample at screening & $x$ & & & & & & & & & & & \\
\hline Assess eligibility & $x$ & $x$ & & & & & & & & & & \\
\hline Check height and weight & $x$ & $x$ & & & & $x$ & & $x$ & & $x$ & $x$ & $x$ \\
\hline Physical examination & $x$ & & & & & $x$ & & & & $\mathrm{X}$ & $\mathrm{X}$ & $\mathrm{x}$ \\
\hline Vital signs & $x$ & $x$ & & $x$ & $x$ & $x$ & & $x$ & & $x$ & $x$ & $x$ \\
\hline 12-lead ECG & $x$ & $x$ & & $x$ & $x$ & $x$ & & $x$ & & $x$ & $x$ & $x$ \\
\hline Adverse events & $x$ & $x$ & $\mathrm{x}$ & $x$ & $x$ & $x$ & $x$ & $x$ & $\mathrm{x}$ & $x$ & $x$ & $x$ \\
\hline Concomitant medications & $x$ & $x$ & $x$ & $x$ & $x$ & $x$ & $x$ & $\mathrm{x}$ & $x$ & $\mathrm{x}$ & $x$ & $x$ \\
\hline Randomization & & $x$ & & & & & & & & & & \\
\hline Dispense study drug & & $x$ & & & & $x$ & & $x$ & & & & \\
\hline Drug accountability, collect unused drug & & & & & & $x$ & & $x$ & & $x$ & $x$ & \\
\hline Uptitration/sham uptitration of study drug & & & & & & $x$ & & $x$ & & & & \\
\hline Local laboratory safety blood sample & & $x$ & $x$ & $x$ & $x$ & $x$ & $\mathrm{X}$ & $x$ & $\mathrm{x}$ & $\mathrm{x}$ & & \\
\hline Central laboratory full blood sample & & $\mathrm{X}$ & & & & $x$ & & $\mathrm{X}$ & & $x$ & $x$ & $x$ \\
\hline Blood and urine samples for biomarkers & & $x$ & & & & $x$ & & $x$ & & $x$ & $x$ & $x$ \\
\hline Central laboratory blood sample for clinical chemistry & & & $\mathrm{x}$ & $\mathrm{x}$ & $\mathrm{x}$ & & $\mathrm{x}$ & & $\mathrm{X}$ & & & \\
\hline Central laboratory blood sample for glycated haemoglobin & & $\mathrm{X}$ & & & & & & & & $\mathrm{X}$ & $x$ & \\
\hline Central laboratory single blood sample for PK & & & & $x$ & & & & $x$ & & & & \\
\hline Central laboratory blood sample for PK & & & & & & $\mathrm{X}$ & & & & & & \\
\hline Central laboratory blood sample for PK"I & & & & & & & & & & $\mathrm{X}$ & & \\
\hline HRQoL questionnaires & & $x$ & & & & $x$ & & & & $\mathrm{x}$ & $x$ & $\mathrm{x}$ \\
\hline Pregnancy test & $\mathrm{x}$ & & & & & & & & & & & \\
\hline \multicolumn{13}{|c|}{ BL, baseline; Dis, discharge; ECG, electrocardiogram; HRQoL, health-related quality of life PD, premature discontinuation; PK, pharmacokinetic. } \\
\hline \multicolumn{13}{|c|}{ * Occurs on day of discharge from hospital only in those hospitalized at visit 1; visit 2 not performed with other patients. } \\
\hline \multicolumn{13}{|l|}{ ₹ Occurs only for individuals up-titrated at visit 5 . } \\
\hline \multicolumn{13}{|c|}{$\S$ Only for individuals up-titrated at visit 7.} \\
\hline \multicolumn{13}{|c|}{ TStudy drug intake at home followed by two samples collected $60-120 \mathrm{~min}$ and $240-300 \mathrm{~min}$ post administration, respectively. } \\
\hline IIPre-dose PK sample at study centre followed by two samples collect & d $30-60 \mathrm{~min}$ an & $180-240$ & 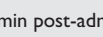 & & & & & & & & & \\
\hline
\end{tabular}

frequency tables. Finerenone treatment groups will be compared with the eplerenone group with respect to these incidences by $\chi^{2}$ tests with continuity correction. In addition, for these special safety parameters, the absolute values and changes from baseline by treatment group will be plotted vs. time. Furthermore, the frequency tables and summary statistics will be repeated by treatment group and uptitration status and separately for each of the stratification levels.

Pharmacokinetic data and HRQoL will be presented with descriptive statistics. Absolute changes in HRQoL scores from baseline to visits 5 and 9 will be analysed using separate ANCOVA models.

\section{Sample size}

In ARTS (IMP 14563; NCT01345656), 37\% of patients experienced a greater than $30 \%$ decrease in plasma NT-proBNP from baseline after 1 month of treatment with finerenone $10 \mathrm{mg}$ once daily. Assuming a time-constant effect, a greater than $30 \%$ decrease in plasma NT-proBNP from baseline at visit 9 (day $90 \pm 2$ ) is expected in $37 \%$ of patients treated with finerenone $5 \mathrm{mg}$ once daily with possible uptitration to $10 \mathrm{mg}$ once daily. No published reports on the proportion of patients with particular percentage changes in plasma NT-proBNP with eplerenone have been found. Therefore, this study is conducted as an exploratory study: that is, no confirmatory testing on the primary efficacy variable or other variables will be done.
Assuming $37 \%$ as the primary efficacy result for finerenone and $21.4 \%$ for eplerenone, a sample size of 130 patients in the finerenone group and 195 patients in the eplerenone group would result in a power of $90 \%$ for a one-sided $\chi^{2}$ test with continuity correction at a significance level of $5 \%$. Sample-size calculations were performed with nQuery Advisor ${ }^{\circledR} 7.0$ (Statistical Solutions, Cork, Ireland). Given the size of these treatment groups, a total of 845 evaluable individuals are needed. The screening failure rate is assumed to be approximately $30 \%$, and $20 \%$ is added to allow for potential dilution of the treatment effect owing to the inclusion of patients who die or discontinue the study drug because of cardiovascular hospitalization or emergency presentation for worsening chronic HF as non-responders in the primary analysis. Considering these rates, approximately 1510 patients will be screened.

\section{Ethical considerations}

The procedures set out in this protocol pertaining to the conduct, evaluation and documentation of the study are designed to ensure that the sponsor and investigators abide by Good Clinical Practice guidelines and follow the guiding principles detailed in the Declaration of Helsinki. The study will be carried out in keeping with applicable local law(s) and regulation(s). Documented approvals from appropriate independent ethics committee(s) or institutional review board(s) will 
be obtained for all participating centres/countries before the start of the study.

\section{Discussion}

Finerenone is a next-generation non-steroidal MRA with greater selectivity for the MR than spironolactone and stronger affinity for the MR than eplerenone in vitro. ${ }^{18}$ Theoretically, a non-steroidal MRA may possess a different ratio of end-organ protective activity vs. undesirable epithelial electrolyte activity in comparison with the available steroidal MRAs. This improved ratio could be achieved by a combination of physicochemical properties that influence plasma transport and tissue penetration, and different affinities of the receptor-drug complex for tissue-specific co-factors. ${ }^{25}$ This theory is supported by two recent preclinical studies. Orena et al. ${ }^{26}$ determined the plasma concentrations of eplerenone and the novel non-steroidal MRA PF-03882845 that were necessary to confer renal protection and to increase serum/plasma $\left[\mathrm{K}^{+}\right]$in a rat kidney injury model. The authors determined a therapeutic index (i.e. the ratio of EC50 for increasing serum/plasma $\left[\mathrm{K}^{+}\right]$to the EC50 for reducing urine albumin levels) of PF-03882845 against hyperkalaemia that was 57 -fold superior to that of eplerenone. ${ }^{26}$ Similarly, Kolkhof et al. ${ }^{16}$ demonstrated that finerenone reduces functional and structural parameters of end-organ failure more efficiently than eplerenone at equinatriuretic doses in preclinical rat disease models.

Data from the phase 2a ARTS study show that finerenone $2.5-10.0 \mathrm{mg} /$ day leads to significantly smaller increases in serum $\left[\mathrm{K}^{+}\right]$and smaller decreases in eGFR than spironolactone $25 \mathrm{mg}$ or $50 \mathrm{mg}$ once daily, with comparable efficacy, as measured by a decrease in plasma NT-proBNP levels and albuminuria, in patients with stable HFrEF and moderate CKD. ${ }^{19}$ Combined with the preclinical data, these results suggest that finerenone could improve outcomes in patients with HF, with a lower risk of hyperkalaemia and worsening renal function than the steroidal MRAs, and should be further investigated in other patient groups.

Although MRAs have not been previously systematically studied in patients with worsening chronic HFrEF who require emergency admission to hospital, evidence from the use of MRAs in other patient groups and the finding that aldosterone and cortisol levels are elevated in these patients suggest that the MR may be an important therapeutic target in HFrEF. ARTS-HF is designed to investigate the safety and potential efficacy of finerenone in a dose range of $2.5-20 \mathrm{mg} /$ day in comparison to eplerenone in a dose range $25 \mathrm{mg}$ every other day to $50 \mathrm{mg} /$ day in patients with worsening chronic HFrEF and concomitant T2DM and/or CKD. As doses of finerenone of $2.5-10 \mathrm{mg}$ once daily were tested in ARTS, the same finerenone dose range was chosen for the initial randomization groups for ARTS-HF. Following a recommendation from the independent DSMB after review of ongoing data on the safety and tolerability of finerenone, three pre-planned treatment arms using higher doses of finerenone of up to $20 \mathrm{mg}$ once daily were introduced.

The primary objective of ARTS-HF is to determine the doses of finerenone that lead to larger proportions of patients who have reductions in levels of plasma NT-proBNP of more than
$30 \%$ relative to baseline, compared with eplerenone. It should be noted that according to international guidelines ${ }^{4,5}$ the usefulness of serial NT-proBNP measurements to improve clinical outcomes in patients with HF is not well established. However, HF therapies proven to have beneficial long-term effects on mortality, such as ACE inhibitors, ARBs, $\beta$-blockers and cardiac resynchronization therapy, tend to lead to a decrease in levels of natriuretic peptide levels over time, ${ }^{27-31}$ and decreasing levels of plasma BNP and NT-proBNP have also been observed during treatment with steroidal MRAs. ${ }^{32-34}$ Although the ASTRONAUT (Aliskiren Trial in Acute Heart Failure Outcomes) study of the effects of aliskiren in hospitalized patients with HF showed decreases in NT-proBNP that were not associated with improved clinical outcomes, ${ }^{35}$ several other studies, including a sub-analysis of the 1742 patients in the placebo arm of the Val-HeFT trial, have indicated that intra-individual changes in plasma NT-proBNP concentrations are a predictor of prognosis in patients with $\mathrm{HF}^{20-22}$ and that the change in plasma NT-proBNP levels is a predictor of clinical events. The percentage of patients with a relative decrease in plasma NT-proBNP of more than $30 \%$ relative to baseline at visit 9 (day $90 \pm 2$ ) as the primary efficacy variable was chosen based on the results of prospective observational studies of the prognostic relevance of changes in plasma NT-proBNP, which showed that decreases of $30 \%$ or more correlate with improved prognosis. $^{22,36,37}$

While the primary endpoint can be considered as a surrogate marker of efficacy, a key exploratory objective of this study is to determine the effects of finerenone on a composite clinical endpoint of death from any cause, cardiovascular hospitalizations, or emergency presentations for worsening chronic HF. It was considered appropriate to use this exploratory endpoint because the rate of such events is expected to be high in the study population and, given the results of preclinical rat studies described above, ${ }^{16}$ a trend towards a more favourable change in this rate in patients receiving finerenone than in those receiving eplerenone is anticipated.

The RALES (Randomized Aldactone Evaluation Study) trial was the first to demonstrate the efficacy of an MRA (spironolactone) in the treatment of patients with severe chronic HFrEF. ${ }^{1}$ Since the EMPHASIS-HF (Eplerenone in Mild Patients Hospitalization and Survival Study in Heart Failure) trial of eplerenone in patients with less severe HFrEF was published in $2011,{ }^{2}$ it has been recognized that MRAs reduce mortality in this population; consequently, future long-term studies investigating a new MRA in individuals with HFrEF must use an active rather than a placebo control. As a result of this consideration, eplerenone was chosen as the comparator in ARTS-HF. Evidence from several studies suggests that eplerenone may be more suitable than spironolactone in patients with chronic HF and T2DM because of the metabolic effects of spironolactone, particularly on glycated haemoglobin. ${ }^{38,39}$ Furthermore, spironolactone is thought to be associated with a higher incidence of hyperkalaemia than eplerenone in patients with CKD because of its longer serum half-life. Given that the proportion of CKD in our study population of patients with worsening chronic HFrEF is expected to be high, the starting dose of eplerenone chosen, $25 \mathrm{mg}$ every second day, is in line with 
the recommended starting dose of eplerenone in patients with an eGFR of $30-60 \mathrm{~mL} / \mathrm{min} .1 .73 \mathrm{~m}^{2}$ in stable HFrEF patients.

In addition to assessing the safety and potential efficacy of finerenone in patients with worsening chronic HFrEF, ARTS-HF will provide information on its effects on HRQoL as well as its pharmacokinetic properties and its optimal dosing in these patients.

\section{Conclusion}

ARTS-HF is a multicentre, randomized, double-blind, active-comparator-controlled, parallel-group phase $2 b$ dose-finding study. It has been designed to assess the potential efficacy and safety of different doses of the non-steroidal MRA finerenone compared with eplerenone in patients with worsening chronic HF and concomitant T2DM and/or CKD presenting to the emergency department. Should our hypothesis prove correct that finerenone treatment has the potential to reduce serum levels of markers of $\mathrm{HF}$ and improve predefined clinical outcomes in these patients, with an acceptable safety profile, this study could open the door to larger clinical outcomes studies in this patient group.

\section{Supplementary Information}

Additional Supporting Information may be found in the online version of this article:

Appendix S1. DSMB members

Figure S1. Timeline of the visits and main procedures of the MinerAlocorticoid Receptor antagonist Tolerability Study-Heart Failure (ARTS-HF).

\section{Funding}

This work was supported by Bayer HealthCare AG. Charlotte Cookson of Oxford PharmaGenesis ${ }^{\mathrm{TM}}$ provided medical writing support funded by Bayer HealthCare AG.

Conflicts of interest: S.D.A., M.B., M.G., L.K., H.K., A.P.M., B.P., P.P., A.A.V., F.Z., and G.F. were members of the Steering Committee for ARTS-HF. S.D.A. has received consulting fees from Bayer HealthCare AG. M.B. has received research support and speaker honoraria from Bayer HealthCare AG, Boehringer Ingelheim GmbH, Medtronic, Inc., Pfizer Inc., Servier and St Jude Medical, Inc. G.F. is a member of the Steering Committee of trials sponsored by Bayer HealthCare AG, Cardiorentis, the European Commission, Medtronic, Novartis and Vifor Pharma. M.G. has received consulting fees for Bayer HealthCare AG, Cardiocell, J\&J, Novartis, Otsuka Pharmaceutical, and Takeda. H.K. has received research grants and consulting fees from Bayer HealthCare AG. L.K. has been a speaker for Bayer HealthCare AG, Novartis, and Servier. N.K.K., S.-Y.K., and C.N. are employees of Bayer HealthCare AG. A.P.M. is a member of the Steering Committee of trials sponsored by Bayer, Novartis, Abbott Vascular, and Cardiorentis. A.P. provided clinical trial support funded by Bayer HealthCare AG. B.P. has received consulting fees for Bayer HealthCare AG, Eli Lilly, and Pfizer Inc., has stock options in Relypsa Inc. and has a patent pending on site-specific delivery of eplerenone to the myocardium. P.P. received speaker honoraria and advisory board member honoraria from Bayer HealthCare AG. A.A.V. has received consulting and speaker fees and/or research grants from Amgen, Bayer HealthCare AG, Cardio3Biosciences, Celladon, Novartis, Merck/MSD, Servier, Takeda, Trevena and Vifor Pharma, and is supported by research grants from the European Commission (FP7-242209-BIOSTAT-CHF) and the Dutch Heart Foundation. F.Z. is a consultant or has received honoraria from Air Liquide, Bayer HealthCare AG, Biomérieux, Biotronik, Boston Scientific, Janssen, Novartis, Pfizer, Resmed, Servier, St Jude and Takeda, has received speaker fees from Mitsubishi, has stocks in CardioRenal diagnosticS and has received grants or research support from BG Medicine and Roche Diagnostics.

\section{References}

1. Pitt B, Zannad F, Remme WJ, Cody R, Castaigne A, Perez A, Palensky J, Wittes J. The effect of spironolactone on morbidity and mortality in patients with severe heart failure. Randomized Aldactone Evaluation Study Investigators. N Engl J Med 1999;341:709-717.

2. Zannad F, McMurray JJ, Krum H, van Veldhuisen DJ, Swedberg K, Shi H, Vincent J, Pocock SJ, Pitt B. Eplerenone in patients with systolic heart failure and mild symptoms. N Engl J Med 2011;364:11-21.

3. Butler J, Ezekowitz JA, Collins SP, Givertz MM, Teerlink JR, Walsh MN, Albert NM, Westlake Canary CA, Carson PE, Colvin-Adams M, Fang JC, Hernandez AF, Hershberger RE, Katz SD, Rogers JG, Spertus JA, Stevenson WG, Sweitzer NK, Tang WH, Stough WG, Starling RC. Update on aldosterone antagonists use in heart failure with reduced left ventricular ejection fraction. Heart Failure Society of America Guidelines Committee. J Card Fail 2012;18:265-281.

4. McMurray JJ, Adamopoulos S, Anker SD, Auricchio A, Bohm M, Dickstein K, Falk V, Filippatos G, Fonseca C, Gomez-Sanchez MA, Jaarsma T, Kober L, Lip GY, Maggioni AP, Parkhomenko A, Pieske BM, Popescu BA, Ronnevik PK, Rutten FH, Schwitter J, Seferovic P, Stepinska J, Trindade PT, Voors AA, Zannad F, Zeiher A, Bax JJ, Baumgartner H, Ceconi C, Dean V, Deaton C, Fagard R, Funck-Brentano C, Hasdai D, Hoes A, Kirchhof P, Knuuti J, Kolh P, McDonagh T, Moulin C, Reiner Z, Sechtem U, Sirnes PA, Tendera M, Torbicki A, Vahanian A, Windecker S, Bonet LA, Avraamides P, Ben Lamin HA, Brignole M, Coca A, Cowburn P, Dargie H, Elliott P, Flachskampf FA, Guida GF, Hardman S, lung B, Merkely B, Mueller C, Nanas JN, Nielsen OW, Orn S, Parissis JT, Ponikowski P. ESC guidelines for the diagnosis and treatment of acute and chronic heart failure 2012: The Task Force for the Diagnosis and Treatment of Acute and Chronic Heart Failure 2012 of the European Society of Cardiology. Developed in collaboration with the Heart Failure Association (HFA) of the ESC. Eur J Heart Fail 2012;14:803-869.

5. Yancy CW, Jessup M, Bozkurt B, Butler J, Casey DE Jr, Drazner MH, Fonarow GC, Geraci SA, Horwich T, Januzzi JL, Johnson MR, Kasper EK, Levy WC, Masoudi FA, McBride PE, McMurray Jj, Mitchell JE, Peterson PN, Riegel B, Sam F, Stevenson LW, Tang WH, Tsai EJ, Wilkoff BL. 2013 ACCF/AHA guideline for the management of heart failure: a report of the American College of Cardiology Foundation/American Heart Association Task Force on practice guidelines. Circulation 2013;128:e240-e327.

6. Juurlink DN, Mamdani MM, Lee DS, Kopp A, Austin PC, Laupacis A, Redelmeier DA. Rates of hyperkalemia after publication of the Randomized Aldactone Evaluation Study. N EnglJ Med 2004;351:543-551.

7. Eschalier R, McMurray JJ, Swedberg K, van Veldhuisen DJ, Krum H, Pocock SJ, Shi $\mathrm{H}$, Vincent J, Rossignol P, Zannad F, Pitt B. Safety and efficacy of eplerenone in patients at high risk for hyperkalemia and/or worsening renal function: analyses of the EMPHASIS-HF study subgroups (Eplerenone in Mild Patients Hospitalization And Survlval Study in Heart Failure). J Am Coll Cardiol 2013;62:1585-1593.

8. Albert NM, Yancy CW, Liang L, Zhao X, Hernandez AF, Peterson ED, Cannon CP, Fonarow GC. Use of aldosterone antagonists in heart failure. JAMA 2009;302:1658-1665.

9. Ezekowitz JA, Bakal JA, Kaul P, Westerhout CM, Armstrong PW. Acute heart failure in the emergency department: short and long-term outcomes of elderly patients with heart failure. Eur J Heart Fail 2008;10:308-314.

10. Gheorghiade M, Braunwald E. Hospitalizations for heart failure in the United States-a sign of hope. JAMA 2011;306:1705-1706.

11. Gheorghiade M, Peterson ED. Improving postdischarge outcomes in patients hospitalized for acute heart failure syndromes. JAMA 2011;305:2456-2457. 
12. Skali H, Dwyer EM, Goldstein R, Haigney M, Krone R, Kukin M, Lichstein E, McNitt S, Moss AJ, Pfeffer MA, Solomon SD. Prognosis and response to therapy of first inpatient and outpatient heart failure event in a heart failure clinical trial: MADIT-CRT. Eur J Heart Fail 2014;16:560-565.

13. Maggioni AP, Dahlstrom U, Filippatos G, Chioncel O, Crespo Leiro M, Drozdz J, Fruhwald F, Gullestad L, Logeart D, Fabbri G, Urso R, Metra M, Parissis J, Persson H, Ponikowski P, Rauchhaus M, Voors AA, Wendelboe Nielsen O, Zannad F, Tavazzi L. EURObservational Research Programme: regional differences and 1-year follow-up results of the Heart Failure Pilot Survey (ESC-HF Pilot). Eur J Heart Fail 2013;15:808-817.

14. Maggioni AP, Dahlstrom U, Filippatos G, Chioncel O, Leiro MC, Drozdz J, Fruhwald F, Gullestad L, Logeart D, Metra M, Parissis J, Persson H, Ponikowski P, Rauchhaus M, Voors A, Nielsen OW, Zannad F, Tavazzi L. EURObservational Research Programme: the Heart Failure Pilot Survey (ESC-HF Pilot). Eur J Heart Fail 2010;12:1076-1084.

15. Edwards NC, Ferro CJ, Kirkwood H, Chue CD, Young AA, Stewart PM, Steeds RP, Townend JN. Effect of spironolactone on left ventricular systolic and diastolic function in patients with early stage chronic kidney disease. Am J Cardiol 2010;106:1505-1511.

16. Kolkhof $P$, Delbeck M, Kretschmer A, Steinke W, Hartmann E, Barfacker L, Eitner F, Albrecht-Kupper B, Schafer S. Finerenone, a novel selective non-steroidal mineralocorticoid receptor antagonist protects from rat cardiorenal injury. J Cardiovasc Pharmacol 2014;64:69-78.

17. INSPRA (eplerenone) tablets: Prescribing information http://www.accessdata. fda.gov/drugsatfda_docs/label/2008/021437s006lbl.pdf (12 January 2015).

18. Bärfacker L, Kuhl A, Hillisch A, Grosser R, Figueroa-Perez S, Heckroth H, Nitsche A, Erguden JK, Gielen-Haertwig H, Schlemmer KH, Mittendorf J, Paulsen H, Platzek J, Kolkhof P. Discovery of BAY 94-8862: a nonsteroidal antagonist of the mineralocorticoid receptor for the treatment of cardiorenal diseases. ChemMedChem 2012;7:1385-1403.

19. Pitt B, Kober L, Ponikowski P, Gheorghiade M, Filippatos G, Krum H, Nowack C, Kolkhof P, Kim SY, Zannad F. Safety and tolerability of the novel non-steroidal mineralocorticoid receptor antagonist BAY 94-8862 in patients with chronic heart failure and mild or moderate chronic kidney disease: a randomized, double-blind trial. Eur Heart J 2013;34:2453-2463.

20. Bayes-Genis A, Pascual-Figal D, Fabregat J, Domingo M, Planas F, Casas T, Ordonez-Llanos J, Valdes M, Cinca J. Serial NT-proBNP monitoring and outcomes in outpatients with decompensation of heart failure. Int J Cardiol 2007;120:338-343.

21. Masson S, Latini R, Anand IS, Barlera S, Angelici L, Vago T, Tognoni G, Cohn $\mathrm{JN}$. Prognostic value of changes in $\mathrm{N}$-terminal pro-brain natriuretic peptide in Val-HeFT (Valsartan Heart Failure Trial). J Am Coll Cardiol 2008;52:997-1003.

22. Pascual-Figal DA, Domingo M, Casas T, Gich I, Ordonez-Llanos J, Martinez P, Cinca J, Valdes M, Januzzi JL, Bayes-Genis A. Usefulness of clinical and NT-proBNP monitoring for prognostic guidance in destabilized heart failure outpatients. Eur Heart J 2008;29:1011-1018.

23. Allen LA, Gheorghiade M, Reid KJ, Dunlay SM, Chan PS, Hauptman PJ, Zannad F, Konstam MA, Spertus JA. Identifying patients hospitalized with heart failure at risk for unfavorable future quality of life. Circ Cardiovasc Qual Outcomes 2011;4:389-398.

24. Dunlay SM, Gheorghiade M, Reid KJ, Allen LA, Chan PS, Hauptman PJ, Zannad F, Maggioni AP, Swedberg K, Konstam MA, Spertus JA. Critical elements of clinical follow-up after hospital discharge for heart failure: insights from the EVEREST trial. Eur J Heart Fail 2010;12:367-374.

25. Kolkhof $P$, Borden SA. Molecular pharmacology of the mineralocorticoid receptor: prospects for novel therapeutics. Mol Cell Endocrinol 2012;350:310-317.

26. Orena S, Maurer TS, She L, Eudy R, Bernardo V, Dash D, Loria P, Banker ME, Tugnait M, Okerberg CV, Qian J, Boustany-Kari CM. PF-03882845, a non-steroidal mineralocorticoid receptor antagonist, prevents renal injury with reduced risk of hyperkalemia in an animal model of nephropathy. Front Pharmacol 2013;4:115.

27. Berry C, Murphy NF, De Vito G, Galloway S, Seed A, Fisher C, Sattar N, Vallance $\mathrm{P}$, Hillis WS, McMurray J. Effects of aldosterone receptor blockade in patients with mild-moderate heart failure taking a beta-blocker. Eur J Heart Fail 2007;9:429-434.
28. Frantz RP, Olson LJ, Grill D, Moualla SK, Nelson SM, Nobrega TP, Hanna RD, Backes RJ, Mookadam F, Heublein D, Bailey KR, Burnett JC. Carvedilol therapy is associated with a sustained decline in brain natriuretic peptide levels in patients with congestive heart failure. Am Heart J 2005; 149:541-547.

29. Fruhwald FM, Fahrleitner-Pammer A, Berger R, Leyva F, Freemantle N, Erdmann E, Gras D, Kappenberger L, Tavazzi L, Daubert JC, Cleland JG. Early and sustained effects of cardiac resynchronization therapy on $\mathrm{N}$-terminal pro-B-type natriuretic peptide in patients with moderate to severe heart failure and cardiac dyssynchrony. Eur Heart J 2007;28:1592-1597.

30. Hartmann F, Packer M, Coats AJ, Fowler MB, Krum H, Mohacsi P, Rouleau JL, Tendera M, Castaigne A, Anker SD, Amann-Zalan I, Hoersch S, Katus HA. Prognostic impact of plasma $\mathrm{N}$-terminal pro-brain natriuretic peptide in severe chronic congestive heart failure: a substudy of the Carvedilol Prospective Randomized Cumulative Survival (COPERNICUS) trial. Circulation 2004;110:1780-1786.

31. Maggioni AP, Anand I, Gottlieb SO, Latini R, Tognoni G, Cohn JN. Effects of valsartan on morbidity and mortality in patients with heart failure not receiving angiotensin-converting enzyme inhibitors. J Am Coll Cardiol 2002;40: 1414-1421.

32. Iraqi W, Rossignol P, Angioi M, Fay R, Nuee J, Ketelslegers JM, Vincent J, Pitt B, Zannad F. Extracellular cardiac matrix biomarkers in patients with acute myocardial infarction complicated by left ventricular dysfunction and heart failure: insights from the Eplerenone Post-Acute Myocardial Infarction Heart Failure Efficacy and Survival Study (EPHESUS) study. Circulation 2009;119: 2471-2479.

33. Tsutamoto T, Wada A, Maeda K, Mabuchi N, Hayashi M, Tsutsui T, Ohnishi M, Sawaki M, Fujii M, Matsumoto T, Matsui T, Kinoshita M. Effect of spironolactone on plasma brain natriuretic peptide and left ventricular remodeling in patients with congestive heart failure. J Am Coll Cardiol 2001;37:1228-1233.

34. Udelson JE, Feldman AM, Greenberg B, Pitt B, Mukherjee R, Solomon HA, Konstam MA. Randomized, double-blind, multicenter, placebo-controlled study evaluating the effect of aldosterone antagonism with eplerenone on ventricular remodeling in patients with mild-to-moderate heart failure and left ventricular systolic dysfunction. Circ Heart Fail 2010;3:347-353.

35. Gheorghiade M, Bohm M, Greene SJ, Fonarow GC, Lewis EF, Zannad F, Solomon SD, Baschiera F, Botha J, Hua TA, Gimpelewicz CR, Jaumont X, Lesogor A, Maggioni AP. Effect of aliskiren on postdischarge mortality and heart failure readmissions among patients hospitalized for heart failure: the ASTRONAUT randomized trial. JAMA 2013;309:1125-1135.

36. Verdiani V, Ognibene A, Rutili MS, Lombardo C, Bacci F, Terreni A, Nozzoli C. NT-ProBNP reduction percentage during hospital stay predicts long-term mortality and readmission in heart failure patients. J Cardiovasc Med (Hagerstown) 2008;9:694-699.

37. Bettencourt P, Azevedo A, Pimenta J, Frioes F, Ferreira S, Ferreira A. $\mathrm{N}$-terminal-pro-brain natriuretic peptide predicts outcome after hospital discharge in heart failure patients. Circulation 2004;110:2168-2174.

38. Yamaji M, Tsutamoto T, Kawahara C, Nishiyama K, Yamamoto T, Fujii M, Horie M. Serum cortisol as a useful predictor of cardiac events in patients with chronic heart failure: the impact of oxidative stress. Circ Heart Fail 2009;2:608-615.

39. Yamaji M, Tsutamoto T, Kawahara C, Nishiyama K, Yamamoto T, Fujii M, Horie M. Effect of eplerenone versus spironolactone on cortisol and hemoglobin $A_{1}(c)$ levels in patients with chronic heart failure. Am Heart J 2010;160:915-921.

40. Hamm CW, Bassand JP, Agewall S, Bax J, Boersma E, Bueno H, Caso P, Dudek D, Gielen S, Huber K, Ohman M, Petrie MC, Sonntag F, Uva MS, Storey RF, Wijns $W$, Zahger D. ESC Guidelines for the management of acute coronary syndromes in patients presenting without persistent ST-segment elevation: The Task Force for the management of acute coronary syndromes (ACS) in patients presenting without persistent ST-segment elevation of the European Society of Cardiology (ESC). Eur Heart J 2011;32:2999-3054.

41. Wright RS, Anderson JL, Adams CD, Bridges CR, Casey DE Jr, Ettinger SM, Fesmire FM, Ganiats TG, Jneid H, Lincoff AM, Peterson ED, Philippides G], Theroux P, Wenger NK, Zidar JP, Jacobs AK. 2011 ACCF/AHA Focused Update of the Guidelines for the Management of Patients With Unstable Angina/ Non-ST-Elevation Myocardial Infarction (Updating the 2007 Guideline): a report of the American College of Cardiology Foundation/American Heart Association Task Force on Practice Guidelines. Circulation 2011;123:2022-2060. 